\title{
A reforma administrativa que ainda não veio: dever estatal de fomento à cidadania ativa e à governança
}

Vanice Regina Lírio do Valle*

\section{O direito administrativo no centro de convergência de forças de conservação e mudança}

Se incerteza e contingência são elementos típicos da pós-modernidade, disso decorre um fenômeno que se tem manifesto, no campo do direito, de forma reiterada no último quartil do século XX e primeira década do século XXI, a saber, a superação das velhas fórmulas dicotômicas como síntese possível da realidade. Assim, se o exercício racional típico da modernidade confiara nas classificações dualistas como um critério científico próprio para empreender as diferenciações e associações em vários campos do conhecimento, a pós-modernidade evidencia que o dualismo é simplificador da real complexidade que se revela por trás dos fenômenos sociais tratados igualmente pelo campo do direito.

Muitas são as concepções dualistas derrubadas nesses tempos de febril reformulação de paradigmas, e entre elas, aquela que segmentava a vida social em esfera privada, "fundada sobre a livre iniciativa individual e estruturada em torno das relações de interação que se estabelecem entre os indivíduos e os grupos...",

\footnotetext{
* Professora do Programa de Pós-graduação em Direito da Universidade Estácio de Sá (Unesa). Pósdoutoranda em administração pela Ebape/FGV. Doutora em direito pela Universidade Gama Filho (UGF) e mestre em direito pela Universidade Estácio de Sá (Unesa). Membro do Instituto de Direito Administrativo do Estado do Rio de Janeiro (Idaerj).
} 
e esfera pública, "condensando as relações de autoridade e de coerção, que integra o conjunto das funções de direção e de gestão da coletividade..." (Chevallier, 2009:82). Indissociavelmente relacionada a essa ruptura de paradigma, temos a reconfiguração da singularidade estatal - alimentada, decerto, também por outros fatores - mas que gera massivos efeitos na reflexão envolvendo o seu braço mais operacional, a saber, a função administrativa, sua disciplina jurídica e suas estruturas de execução.

A desmistificação do Estado, como titular único do conhecimento e da capacidade de revelar e concretizar o interesse público, abre um leque de possibilidades no que toca às relações que podem se estabelecer entre administração e sociedade, refletindo na diversidade de modelos a pluralidade de que passa a se revestir a própria sociedade a que ele serve.

O Estado, identificado na sua função executiva como administração pública, remanesce importante ator no cenário, mas sua presença pública passa a se caracterizar não mais por sua extensão, mas sim na lição de Rodríguez-Aranda (2005:11-39), por sua intensidade. Associam-se ao Estado características e finalidades que nunca antes lhe foram creditadas: promover a articulação da solidariedade (Sorrentino, 2003:31), abrir-se à dimensão da governança (Aguilar Villanueva, 2006), garantir a horizontalidade de direitos fundamentais por intermédio dos deveres especiais de proteção (Mendes, 2004:117-119).

Mas todo o momento de mudança de paradigma é complexo - já advertiam Ost e Kervoche (2002:14-16) - , podendo determinar de parte da ciência jurídica distintas reações. A primeira delas é o abandono imediato do paradigma dominante, acolhendo entusiasticamente o modelo novo. Todavia, ainda é possível a tentativa de conservação do paradigma anterior, seja pela qualificação dos novos fenômenos em velhas categorias, seja pela extensão indevida do paradigma em revisão a hipóteses que por ele não seriam alcançadas, tudo sob o argumento de que se está - uma vez mais, na lição de Ost - "superando obstáculos epistemológicos".

Se os últimos 20 anos se revelaram férteis em iniciativas voltadas à concretização dessa nova administração pública - seja na sua dimensão estrutural e institucional, seja na normatividade aplicada - , não é menos verdade que o processo de transição tem enfrentado exatamente as dificuldades em relação às quais advertiam os autores belgas citados, manifestas especialmente nas reações de conservação do velho paradigma.

O direito - ciência intrinsecamente relacionada à estabilidade que ele busca conferir na regulação das relações sociais - manifesta uma inclinação natural à conservação, podendo ser posto em choque com as exigências atuais da função administrativa, que se caracterizam pela dinâmica e adaptabilidade. 
Assim é que num plano e noutro - na instrumentalização e compreensão das novas possibilidades institucionais, e ainda no desenvolvimento de uma capacidade normativa compatível com esses tempos de fluidez - , o direito tem se revelado refém dessa tensão intrínseca entre conservação e mudança no plano da moldura da ação estatal. Com frequência, o direito cede à tentação da busca do enquadramento de novas realidades em velhas categorias, numa visão retrospectiva dos novos fenômenos. Mais ainda, não tem sido rara a opção igualmente apressada se não conservadora - que felizmente, não se pode afirmar predominante na doutrina nacional, mas ainda assim é presente - pela pecha de "inconstitucional" às iniciativas menos familiares, buscando na constituição autoridade para um argumento que não encontrou numa reflexão mais propositiva esse mesmo epíteto.

Fato é que o direito, caso não mantenha uma fina sintonia com as provocações da nova realidade, pode vir a se transformar em verdadeira cláusula de bloqueio ao desenvolvimento, numa sobrevalorização dos meios sobre os fins. Esse é um risco que já se percebe na aproximação excessivamente cautelosa que se tem empreendido a ferramentas jurídicas contratuais ou de modelagem institucional apresentadas - propostas ou mesmo preceituadas - aptas a enfrentar o complexo conjunto de atividades a que a administração hoje se dedica.

O momento atual envolve, uma vez mais, a formulação de alternativas de reformulação da estrutura orgânico-institucional da administração pública. O Ministério do Planejamento, Orçamento e Gestão, por intermédio da Portaria no 426, de 6 de dezembro de 2007, vem compor comissão com o objetivo de elaborar anteprojeto de lei orgânica da administração pública federal e entes de colaboração, buscando na inegável expertise dos juristas que a integram, a contribuição que a ciência do direito possa oferecer ${ }^{1}$ aos desafios atinentes à instrumentalização da administração pública de uma arquitetura institucional que favoreça ao desenvolvimento dos importantes misteres que hoje the são propostos em tempos de incorporação de uma teoria constitucional da solidariedade (Cabo Martín, 2006), que se revele capaz de liderar a caminhada da efetivação dos direitos fundamentais nas suas múltiplas dimensões e funcionalidades.

Alinham-se, portanto, nas presentes considerações, algumas armadilhas que podem se apresentar a esse processo de reformulação do ferramental disponível à administração pública. Numa perspectiva de que, por vezes, o bloqueio maior reside não na disciplina jurídica em si, mas na própria cultura de conservação que, sendo própria à ciência, contamina, por vezes, seus cultores. É preciso que o direito - especialmente o direito administrativo - encontre o seu ponto de equilíbrio entre velhos e novos padrões estruturais, recuperando uma capacidade propositiva

\footnotetext{
${ }^{1}$ Os trabalhos da referida comissão foram concluídos em julho de 2009. As respectivas conclusões e proposta de projeto de lei estão disponíveis em: <http://www.planejamento.gov.br/secretarias/upload/ Arquivos/seges/comissao_jur/arquivos/090729_seges_Arq_leiOrganica.pdf $>$. Acesso em: 3 set. 2009.
} 
que favoreça o avanço, sem prejuízo à juridicidade. Em coerência com essa percepção, completa-se este artigo com um esboço de agenda para as futuras inovações no campo da reforma administrativa, provocação cujo principal objetivo é estimular o debate nesse tema que a todos afeta, seja na sua condição de operador do direito, seja na condição de cidadão.

\section{A "resistência passiva" à trajetória de mudança da administração burocrática ao paradigma gerencial}

No tema de estruturação da administração pública, a Carta de 1988 em seu esforço de transição para um regime qualificado como democrático-burocrático, identifica o Estado como "o campo da auto-organização dos interesses coletivos. A sociedade civil existe fora dele, mas voltada para ele, através do qual plasma suas demandas específicas" (Lopes, 2008:195). Essa opção de arranjo institucional de um lado sublinha a importância da estrutura burocrática no desenvolvimento de sua função de coordenação dos referidos interesses coletivos. O texto original da constituição se apresenta assim, no que toca ao desenho estatal, fortemente comprometido com sua democratização (instrumentalizada pelo ferramental de controle que ali se erigira), a descentralização e a profissionalização da burocracia (Abrúcio, 2007:67-86).

De outro lado, o texto fundamental ao Estado propõe um papel de articulador de um debate em relação às demandas formuladas pela sociedade, que se trava inicialmente entre ele e as forças sociais, mas também tematiza uma possibilidade de ação reconhecida a esse mesmo Estado, de coordenação em rede entre suas próprias possibilidades de ação e, ainda, aquelas atinentes aos múltiplos agentes sociais. Essa concepção é refletida por todo o nosso texto constitucional, em seus compromissos, de um lado, com a dimensão social do Estado de direito e, de outro lado, com a ênfase na importância da participação popular (Valle, 2002:75-139).

Se a formação da estrutura burocrática se revelava tarefa beneficiária da experiência no Brasil e alhures - e, portanto, exigia um grau de compromisso na sua implementação, mas não necessariamente de inventiva, na medida em que se beneficiava de um acervo já construído de conhecimento - , o mesmo não se pode dizer em relação a essa atuação confiada ao Estado, de arena de debate em relação às demandas específicas voltadas a ele pela sociedade. Acresça-se a circunstância de que esse volume de demandas sociais entra em curva exponencial, com a vasta enunciação de direitos fundamentais a que se dedica a Carta de Outubro, cuja 
concretização, na lição de Werneck Vianna, desde o momento constituinte, se supunha devesse passar - à vista da então identificada crise de legitimidade - pelo envolvimento e postulação expressos pela própria sociedade. ${ }^{2}$

O desenho originário do texto constitucional, como se sabe, sensível ao debate neoliberal em relação às funções e dimensões do Estado, rapidamente sofreu modificações no rumo da desestatização. Associado a esse tipo de onda reformista, seguia-se sempre a reconfiguração da administração pública - fenômeno que se manifestava em todo o mundo ocidental nas décadas de 1980-90³ - de quem se esperava um incremento da capacidade gerencial como contrapartida da redução do tamanho do Estado.

A questão posta - na lição de Rezende (2009:348) - para os gerencialistas é "que desenhos institucionais permitem reconfigurar a eficiência dos modelos de gestão?". A partir dessa indagação terá lugar um movimento de reconfiguração da ação estatal, na sua moldura normativa e institucional - não o primeiro, decerto, já que o Brasil experimentou reformas administrativas antes das perplexidades propostas pela globalização (Costa, 2008:829-874); remontando mesmo suas primeiras manifestações ao período colonial.

Alcançada a década de 1990, o grande movimento reformista de cunho gerencialista tem lugar, com foco na dimensão institucional, cultural e de gestão propriamente dita, tudo nos termos do plano diretor da reforma do Estado. ${ }^{4}$ Essa linha principal de atuação, traçada no documento retor da reforma administrativa, à vista da multiplicidade de aspectos relacionados à administração pública nacional constitucionalizados, ou quando menos, insculpidos em normas de caráter nacional, ou ainda reservados à iniciativa legislativa da União, veio a exigir para a sua consolidação ponderáveis esforços orientados à revisão do marco legal respectivo.

Inobstante o fato político concreto da aprovação da Emenda Constitucional no 19 - motor principal do referido processo de revisão do marco legal - com substantivas modificações em velhos tabus da burocracia nacional, ${ }^{5}$ não constitui propriamente novidade no meio acadêmico a afirmação de que esse esforço de

\footnotetext{
2 "Assim, se o legislador está vinculado constitucionalmente aos direitos fundamentais, que são direitos de eficácia imediata, cabe à sociedade, por meio dos mecanismos institucionais estabelecidos, ao lado dos atores da representação política ou sem eles, lutar por sua aplicabilidade" (Werneck Vianna, 2008).

${ }^{3}$ É de Secchi (2009) a notícia de que os elementos apontados como ativadores dessas ondas de "modernização" na administração pública em todo o mundo são a crise fiscal do Estado, a crescente competição territorial pelos investimentos privados e mão de obra qualificada, a disponibilidade de novos conhecimentos organizacionais e tecnologia, a ascensão de valores pluralistas e neoliberais, e a crescente complexidade, dinâmica e diversidade das nossas sociedades.

${ }^{4}$ Plano diretor da reforma do Estado. Disponível em: <http://www.planalto.gov.br/publi_04/ COLECAO/PLANDI.HTM>. Acesso em: 27 ago. 2009.

${ }^{5}$ No campo dos tabus superados pela Emenda Constitucional no 19, desponta a previsão da admissibilidade de demissão do servidor público estável, incorporada aos termos do art. 169 da CF/88.
} 
inovação institucional, embora tenha logrado relevantes avanços, ${ }^{6}$ não alcançou toda a potencialidade de resultados que eram atribuídos como possíveis.

É Abrúcio (2007:73) quem aponta - não obstante outros fatores como a nossa pouca cultura na concretização de reformas administrativas construídas na base da negociação e de um processo decisório menos concentrador - que importante elemento de constrição das possibilidades da reforma administrativa foi a "prevalência da agenda do ajuste fiscal", a partir de uma visão economicista predominante. Na mesma linha de consideração, Rezende (2009:359) sublinha a identificação empreendida por importantes atores políticos - o Ministério do Planejamento, Orçamento e Gestão, a Casa Civil etc. - da reforma administrativa como uma questão mais diretamente associada aos processos de redução de pessoal e de controle de custos com a máquina administrativa, do que em introduzir mudanças substanciais nos arranjos institucionais existentes, mesmo que estes fossem cruciais para a elevação do desempenho.

Se esse cenário político já determinou limitações ao conteúdo da intervenção constitucional em matéria de reforma administrativa, não menos significativa é a verdadeira "resistência passiva" que se segue ao desenvolvimento, ainda, no plano infraconstitucional, das modificações estruturais que se tenha logrado alcançar. Os exemplos são múltiplos e passam tanto pela obstrução do eventual processo legislativo exigível para a implementação das propostas da reforma, como pela censura judicial das medidas de concretização.

Duas ilustrações para reforço do ponto. No campo da obstrução legislativa, a ilustração mais candente é aquela relacionada à efetiva implantação das fundações estatais de direito privado. Assim é que o PLC 92, que disciplina as áreas em relação às quais se tenha por possível a criação, no plano federal, de fundações estatais de direito privado, não avança na pauta do Congresso Nacional por conta da velha polêmica em torno das supostas pretensões de privatização de atividade que se sustenta deva ser típica do Estado, ${ }^{7}$ denunciadas pelos segmentos corporativos implicados na temática.

\footnotetext{
${ }^{6}$ O Ministério de Planejamento, Orçamento e Gestão sintetizou no documento denominado "Balanço da reforma do Estado no Brasil: a nova gestão pública", a avaliação envolvendo vários prismas de análise, dos resultados decorrentes da referida reforma. Disponível em: <http://www.cedec.org.br/ files_pdf/BalancodareformadoEstadonoBrasil.pdf>. Acesso em: 29 ago. 2009.

${ }_{7}$ A área, por excelência, em relação à qual se cogita prontamente o uso dessa nova modelagem institucional é a saúde, o que tem motivado o bloqueio da deliberação legislativa em nome da proteção contra a "privatização" da saúde, que decorreria da aplicação à instituição que promova esses serviços, de um regime jurídico com derrogação parcial das cláusulas próprias ao regime público. Registre-se que em arenas menos expostas à atenção nacional, o tema avançou, com a aprovação das respectivas leis complementares, e mesmo leis ordinárias de criação de fundações estatais de direito privado no campo da saúde. Sergipe e Rio de Janeiro são dois exemplos de ciclo legislativo completo no tema. Na Bahia, por sua vez, já se tem a aprovação da lei complementar requerida pelo art. 37, XIX da CF, estando pendentes de aprovação as respectivas leis ordinárias autorizadoras da criação das entidades fundacionais, por força especialmente do processo de consulta pública que lá se empreendeu aos detalhes da modelagem das referidas entidades.
} 
A hipótese envolve manifestação típica do fenômeno determinante da inação parlamentar classificada por Dixon (2007:391-418) como burden of inertia e que traduz um juízo político de parte do legislativo, segundo o qual o dissenso no tema se apresenta de tal forma aprofundado, que do ponto de vista eleitoral revela-se mais prudente suportar os ônus de manter-se inerte, do que enfrentar a reação dos interesses porventura contrariados na concretização da deliberação. ${ }^{8}$

Em matéria de censura judicial às novas alternativas de configuração de modelos institucionais, desponta a polêmica em torno do regime jurídico aplicável aos servidores de agências reguladoras, com o deferimento pelo STF, relator o ministro Marco Aurélio, de medida liminar na ADIn no 2.310, promovida contra cláusulas da Lei no 9.986/2000, que assinalava o regime celetista como aquele de regência do vínculo entre servidor e as referidas entidades da administração. $\mathrm{Na}$ ocasião, sob o argumento de que entre as funções próprias às agências reguladoras havia expressão do poder de política, entendeu o relator deferir a providência de urgência em 19 de dezembro de 2000, suspendendo os efeitos dos dispositivos legais contidos na mencionada Lei n 9.986/2000 que adotavam o regime celetista em relação a esses mesmos servidores. A demanda culminou por não merecer solução de mérito, posto que decretada a perda de objeto em 9 de dezembro de 2004, por força da edição da Lei no $10.871 / 04$, que em seu art. 37 inclinava-se à orientação do STF, revogando os dispositivos antes inquinados de inconstitucionais.

Nessa hipótese, o bloqueio decorrente da decisão judicial determinou verdadeira paralisia na sequência de implementação do modelo das agências reguladoras, ${ }^{9}$ que, na pendência em relação a que regime jurídico admissível adotar quanto a seus servidores, viam-se impedidas de promover os respectivos concursos públicos, enfim, de investir em sua consolidação institucional. ${ }^{10} \mathrm{O}$ resultado foi

\footnotetext{
${ }^{8} \mathrm{O}$ bloqueio parlamentar à edição da norma cogitada pelo art. 37, XIX, CF vai se revestindo de outros desdobramentos, à medida que a matéria tem encontrado alguma repercussão à tese de que a referida lei complementar deva se revestir de caráter nacional - consulte-se, nessa linha de cogitação, a manifestação da Advocacia-Geral da União na ADI no 4.247, em que aponta como suposta causa de nulidade da Lei Complementar Estadual no 118/07, do estado do Rio de Janeiro, que justamente elege, no âmbito daquela entidade federada, a atividade de saúde como suscetível de execução por intermédio de fundações estatais de direito privado.

${ }^{9}$ A leitura da página de acompanhamento da referida medida judicial no site correspondente do STF aponta que, não obstante se cuidar de provimento liminar, suscetível, portanto, de ratificação pelo plenário, o feito se viu obstruído no seu processamento por questões adjetivas, atinentes a uma suposta prejudicialidade entre essa demanda e aquela contida na ADIn no 2.315 (em que se debatia a chamada quebra do regime jurídico único), e ainda, a problemas regimentais relacionados à substituição de relatoria. Fato é que passados quatro anos, nem sequer a ratificação da liminar se dera ainda pelo plenário.

${ }^{10}$ Manifestação típica de absoluta inversão foram os efeitos concretos determinados pela providência de urgência. Isso porque, premidas pelo imperativo de continuidade de suas atividades, sem a possibilidade de convocação dos respectivos concursos, várias agências reguladoras passaram a operar com o uso de contratações temporárias - vínculo em que a insegurança se apresentava ainda mais agravada que na relação celetista, apontada como insuficiente à garantia de estabilidade de quem desenvolvia função de polícia.
} 
decisão pragmática de capitulação concretizada pela citada Lei nº 10.871/2004, que, embora tenha tido por resultado - decerto - viabilizar o provimento de pessoal, expressou o abdicar de um aspecto daquela modelagem institucional que se reputava relevante, prevalecendo o velho paradigma da estabilidade como pedra de toque da independência funcional.

Ainda no campo do controle judicial às inovações legislativas atinentes à reforma dos padrões institucionais ou de operação do Estado, parece relevante destacar certa estratégia judicial, que se beneficia do transcurso do tempo - e dos resultados concretos dele decorrentes - como aliado, para motivar sua decisão a partir de experimentalismo institucional concretizado. Afinal, é de se reconhecer que também o STF, no exercício de sua função institucional, tem em conta que uma lei submetida a controle de constitucionalidade pode envolver - no caso de procedência - a censura à opção originária de outro poder. ${ }^{11}$ Compreensível, portanto, que em casos em que o juízo de inconstitucionalidade pretendido se insira numa obscura zona cinzenta de incertezas, socorra-se a Corte, como elemento de argumentação, dos resultados concretos que já decorram da iniciativa.

Exemplo notável dessa situação foi a decisão cunhada pelo STF na ADIn no 1.923, relator o ministro Eros Grau, promovida em face da Lei no 9.637/98, que disciplinava a figura das organizações sociais. Ajuizada a ADIn em 1ํ de dezembro de 1998, o julgamento em relação ao deferimento de medida liminar requerida se iniciou em 24 de junho de 1999, mas somente se completou em 2 de fevereiro de 2007 - quase 8 anos depois - quando as experiências de implementação de organizações sociais, muitas delas plenamente com sucesso e citadas no voto do ministro Gilmar Mendes, transformam-se em argumento para o indeferimento da tutela de urgência. ${ }^{12}$

Os exemplos de obstaculização a novas alternativas de desenvolvimento da ação pública poderiam se multiplicar, seja com fenômenos mais visíveis como o apontado bloqueio legislativo e a censura judicial desenvolvida sob forte inspiração de aplicação a novas realidades de velhos paradigmas; seja através daquele trabalho mais sutil de "resistência passiva", que é a relativa indiferença doutrinária em relação às modalidades de manifestação do agir estatal que buscam in-

\footnotetext{
${ }^{11}$ É de Friedman interessante panorâmica dos fatores políticos a interferirem no exercício da judicial review, destacando, entre vários, os elementos de constrição decorrentes das relações entre poderes (Friedman, The politics of judicial review. Texas Law Review, v. 84, p. 257, 2005; NYU, Law and economics research paper, no 06-05; NYU, Law school, public law research paper, no 06-04. Disponível em: <http:// ssrn.com/abstract=877328>. Acesso em: 29 ago. 2009.

${ }^{12}$ A ementa da referida decisão de indeferimento de liminar (DJ de 21-9-2007), em seu item 2, assim se expressa: "Afastamento, no caso, em sede de medida cautelar, do exame das razões atinentes ao fumus boni iuris. O periculum in mora não resulta no caso caracterizado, seja mercê do transcurso do tempo - os atos normativos impugnados foram publicados em 1998 - seja porque no exame do mérito poder-se-á modular efeitos do que vier a ser decidido, inclusive com a definição de sentença aditiva".
} 
corporar as novas relações de colaboração e parceria que as entidades estatais são chamadas a desenvolver entre si e com a sociedade civil.

Observadas as devidas exceções, no geral a reação doutrinária a novas figuras institucionais ou mesmo contratuais - especialmente aquelas que envolvem a ampliação das relações de consensualidade - tem sido de reserva, abdicando assim o direito de contribuir na cunhagem dos reais contornos dessas formas relacionais que buscam promover a articulação de esforços disponíveis para além do âmbito estrito da administração interessada.

Eis aí uma primeira armadilha às iniciativas relacionadas à reformulação de instrumentos disponibilizados ao agir estatal: manter com elas uma aproximação conservadora, orientada pelos velhos paradigmas do Estado como executor único das atividades públicas; ou ainda permitir que as reações (naturais) a uma modelagem nova para atender aos desafios que o século XXI propõe a essa estrutura de organização do poder a serviço da sociedade funcionem como verdadeiro bloqueio à real exploração das potencialidades das propostas de modelos institucionais ou relacionais que venha a ser proposto à administração pública.

A prevenção a esse risco estará a exigir do operador do direito e do administrador público, a percepção de que se o Estado muda, isso necessariamente se refletirá na ação que dele se deseja e, por certo, nos mecanismos que se disponibilizar à concretização dessa mesma atuação - que hão de passar pela mesma reoxigenação que passou a própria compreensão do papel do Estado.

\section{O argumento formal de oposição: conflito intrínseco entre flexibilização e controle}

No item 2 foram apontadas manifestações da resistência oferecida antes - e ainda hoje presente - em relação às propostas de aprofundamento de reformas administrativas. Cumpre prosseguir na análise de uma das objeções de ordem técnica apontadas à incorporação de um modelo de maior inspiração gerencial, a saber, os riscos inerentes ao controle.

Remonta ainda ao momento de aprovação em si da Emenda Constitucional no 19 o relato de que uma objeção importante às propostas de reformulação de padrões de ação estatal calcadas na flexibilização envolvia os supostos riscos ao controle - notadamente, o controle que se reputasse instrumental ao grande vetor de orientação do momento, a saber, o ajuste fiscal.

Em verdade, a objeção parece - desde o início - deslocada, seja do ponto de vista de premissa, seja de mérito.

Como premissa, a oposição aos modelos de administração pública orientados ao "gerencialismo", portanto revestidos de mais flexibilidade, parte do pressupos- 
to de que há uma espécie de oposição entre o modelo burocrático - voltado por excelência ao controle por processos - e aquele gerencial, que orientado ao resultado, ver-se-ia privado dos mecanismos de controle. Ora, o equívoco é visível; a diferença entre um e outro modelo reside não da presença ou ausência de controle, mas no "foco" dessa mesma atividade de monitoramento, que se desloca do processo para o resultado, ${ }^{13}$ harmonizando-se ainda com a introdução do parâmetro da eficiência como princípio constitucional a reger a administração pública.

A adoção de formas mais flexíveis de estruturação e relacionamento da administração pública envolve, na lição de Rezende, ${ }^{14}$ uma contraposição de pontos de vista entre o que se possa efetivamente entender por ganho de performance: se esse conceito se associa ao ajuste fiscal, dá-se a sobrevalorização do controle centralizado e a rejeição à flexibilização; se ao contrário, a mudança institucional se associa a desempenho, o afastamento do modelo burocrático se afigura como central. A valorização a um só tempo de ambos os vetores (ajuste fiscal e mudança institucional), como se teve e ainda tem presente no cenário da administração pública brasileira, culmina por produzir incentivos conflitantes, o que decerto contribui para as falhas de implementação.

O problema parece residir, em verdade, num estranhamento relacionado à incorporação de um modelo de controle que, distanciando-se do padrão formalista próprio da administração burocrática, incorpore outros vetores de aferição da eficiência do resultado concretamente obtido, vis-à-vis os eventuais ganhos decorrentes da efetiva concretização das relações de parceria e incorporação da sociedade como agente do desenvolvimento do público não estatal. Se é possível o controle fora das fronteiras estreitas do procedimento burocrático rígido, descaracterizado resta o conflito entre ajuste fiscal e flexibilização, uma vez que a última será possível sem os ganhos exigidos pelo primeiro. ${ }^{15}$

Essa também - a rigor - parece ser uma falsa questão ou uma questão superdimensionada. Afinal, a emancipação do controle público das estreitas frontei-

\footnotetext{
13 “O principal elemento comum desses modelos é a preocupação com a função controle. No caso do modelo burocrático, as características de formalidade e impessoalidade servem para controlar os agentes públicos, as comunicações, as relações intraorganizacionais e da organização com o ambiente. A função controle é uma consequência de um implícito julgamento de que os funcionários públicos se comportam de acordo com a teoria X de McGregor (1960). A função controle na APG está presente tanto no aspecto da capacidade de controle dos políticos sobre a máquina administrativa quanto no controle dos resultados das políticas públicas..." (Secchi, 2009:364).

${ }^{14}$ Rezende (2002). Disponível em: <http://www.scielo.br/scielo.php?script=sci_arttext\&pid=S0102-6909 2002000300008\&lng=en\&nrm=iso>. Acesso em: 29 ago. 2009.

${ }^{15}$ Indicador expressivo das potencialidades de um novo controle voltado à eficiência - e que, portanto, se emancipa das pautas procedimentais do controle burocrático - é a ênfase conferida pelo Promex - Programa de Modernização do Controle Externo dos Estados, Distrito Federal e Municípios à auditoria operacional, que, em oposição à tradicional auditoria de regularidade, tem em conta não somente as dimensões de regularidade contábil ou legal, mas os vetores da economicidade, eficiência, eficácia e efetividade.
} 
ras da regularidade formal é processo consolidado em tempos de republicanismo, democracia e Estado de direito.

A lição de Dromi (2005:37) ao tema é preciosa: “Gobierno y control es la fórmula orgánica de la estructura hipermoderna del poder, para que a los que mandan no les falte poder, y a los que obedecen, no les falte libertad".

O desafio de controle da função administrativa, portanto, já está posto - e não decorre especificamente da flexibilização dos mecanismos possíveis de concretização do agir estatal; mas sim da complexificação mesmo das tarefas e do ambiente onde hoje se desenvolve a função administrativa. Esse novo controle, em verdade, exige uma conjugação de saberes que vai além do direito - mas dele não pode prescindir -; e nisso atinge outra dificuldade com que se confronta a ciência do direito, que é a imprescindibilidade de abertura cognitiva a outras áreas do conhecimento. ${ }^{16}$

A par da abertura cognitiva nas áreas de saber sistematizado - economia, administração, estatística, sociologia, antropologia, entre tantas outras - o controle na pós-modernidade envolve a incorporação de outros vetores de atuação hoje reputados imprescindíveis à administração. O princípio da realidade (Beltrán Villalva, 2000:162) recomenda o cuidadoso exame ao entorno e fenômenos sociais - não para meramente conceder-lhe reconhecimento e respeito, mas como etapa indispensável a um agir administrativo que pretende sobre ela interferir e provocar a mudança. A abertura à experiência - classificada por Rodríguez-Aranda Muñoz (2006:27), como atitude básica do parâmetro ético que deve reger à construção das políticas públicas - se beneficia do aprendizado empírico havido. Todos esses elementos, por sua vez, hão de ser combinados - ainda na lição do jurista espanhol (Rodríguez-Aranda Muñoz, 2006:29) - num exercício do chamado pensamento compatível, que não se encaixa nos modelos rígidos e planos, e que tem capacidade para conciliar o pessoal e o coletivo, o estatal e o civil, a liberdade e a ordem, o mercado e a regulação político-econômica.

Mais ainda, essa nova dimensão de controle é de incorporar outro fenômeno que também se apresenta ao direito administrativo, que é a diferenciação das funções estatais, que associada à especialização decorrente do aprofundamento das complexidades determina o repensar das pretensões de aplicação de um padrão uniforme, inclusive de regime jurídico, a todas essas distintas frentes de atuação.

É de Beltrán Villalva (2000:45) a advertência de que as grandes organizações públicas são realmente constelações de fragmentos de difícil coordenação e impensável redução a uma unidade. Se assim o é, a pretensão de aplicabilidade de um modelo de controle único, "universalmente válido" a qualquer faceta de ati-

\footnotetext{
${ }^{16} \mathrm{O}$ tema já foi desenvolvido em texto anterior: Valle, Vanice Regina Lírio do. O direito narciso: nova ameaça à jusfundamentalidade dos direitos. A\&C. Revista de Direito Administrativo \& Constitucional, v. 28, p. 27-44, 2007.
} 
vidade estatal, se apresenta como incompatível com a realidade do agir estatal do século XXI.

Diante desse cenário, o que se tem é que os desafios estão concretamente postos à realidade da administração e, portanto, o argumento das dificuldades na implementação do controle não pode se sobrepor à questão principal, que consiste em instrumentalizar a administração pública ao desenvolvimento de suas funções típicas. A insistência nos modelos rígidos, originários dos velhos paradigmas da administração weberiana, implicará o vício de raciocínio apontado por Ost e Kerchove (2002:14-16), da aplicação às novas realidades, dos velhos paradigmas, gerando para o direito um "déficit" de funcionalidade, uma incapacidade para oferecer resposta, contra a qual nessas considerações se adverte.

Segunda armadilha contra a qual se adverte no trabalho do operador do direito na cunhagem à interpretação das novas formas de desenvolvimento da ação estatal - sejam as de caráter institucional, sejam as de caráter negocial - reside no temor quanto às possibilidades de controle. É preciso efetivamente incorporar a ideia de que o controle da ação estatal, em pleno século XXI, estará relacionado menos a fórmulas tradicionais conhecidas e mais à instalação de uma "cultura de controle", graças à qual a energia fiscalizadora da cidadania passa a engrossar os ativos da sociedade política (Dromi, 2005:20). Nesses termos, a flexibilização em si da forma de execução da atividade estatal não se apresenta como um óbice ao controle, mas sim como a provocação à construção de mecanismos que possam enriquecer essa atividade de fiscalização para além das fronteiras da forma, alcançando os resultados e o seu impacto sobre a cidadania.

É essa constatação que permite a abordagem da última armadilha aos próximos passos da busca de novos modelos de ação estatal: a rejeição à cidadania ativa e às suas potencialidades de contribuição para com a atuação estatal.

\section{Pluralismo, cidadania ativa e modelos de atuação estatal: esboço de agenda}

É a necessidade inconteste de adaptação do Estado às reivindicações provenientes da sociedade civil em tempos de pluralismo que consagra os movimentos de reforma como elemento da base filosófico-política de sua expressão no século XX (Bento, 2003:9-10). O caminho da reforma administrativa - adotado no cenário brasileiro antes e ainda em pauta uma vez mais - harmoniza-se com a percepção de que fadada ao fracasso estaria uma pretensão de recomeço, a partir do zero, abdicando de todo o recebido (Rodríguez-Arana Muñoz, 2005:24). Todavia, tanto mais orientada ao sucesso estará a reforma, quanto mais ela parta do reco- 
nhecimento da complexidade do real e da constatação das limitações que sobre ela possam incidir.

\section{Direito administrativo: da rigidez à governança}

Na perspectiva das limitações imputáveis às reformas administrativas, o gerencialismo - incorporado pelo movimento traduzido pela Emenda Constitucional no 19 - apontava que o direito administrativo como compreendido "...constituiria um quadro rígido, um verdadeiro entrave, que é um empecilho para a ação, um obstáculo para a mudança; não existiria eficácia administrativa sem afrouxamento das limitações que ele impõe..." (Chevallier, 2009:88).

Ocorre que o direito administrativo reconhece que a orientação finalística do Estado à ideia-matriz da centralidade da pessoa determina uma irreversível configuração de suas relações com esse mesmo destinatário de sua atuação. Nesse sentido, compromete-se com a imprescindibilidade da abertura da administração à interação com a sociedade e com os vários segmentos que nela se veem representados; não somente para identificar e sintetizar as exigências e necessidades apresentadas por ela ao Estado, mas também para determinar, em concreto, qual a maneira mais adequada de atendê-las (Sorrentino, 2003:214).

Curiosa a ilustração de Alejandro García Nieto (2008:47), que destaca que todo o cenário de mudanças não despiu o Estado de seu mister de busca da coesão social; todavia, agora se apresenta como o hub de atividades que conectam distintos atores dos mais diversos campos: atividade, regiões, culturas, profissões e interesses.

O cenário, portanto, é de um direito administrativo que tem em conta um Estado e um poder que não envolve mais tão somente à ideia de dominação, mas que busca empreender ao intercâmbio necessário à apreensão do interesse público num contexto de interações entre agentes múltiplos e plurais. O quadro de transformações evidencia igualmente as relações de interdependência, não apenas entre os vários Estados nacionais, mas também entre Estado e sociedade: o reforço à participação e ao papel da sociedade civil permite reconciliar a cidadania com suas instituições (Cabanes, 2004:43-44).

Essa interdependência - que se inicia a partir da evidência empírica de que a ação estatal não tem mais sentido se descolada do querer do móvel principal desse mesmo agir, a saber, a pessoa humana - culmina por determinar um questionamento que envolve a suficiência de um governo (ainda que eficiente e gerencial) para conduzir a sociedade a que ele se dirige. Abertura a novas relações de conexão entre Estado e sociedade evidencia que essa ação pública poderia se beneficiar da presença de atores adicionais; o problema deixa de ser de "eficiência" para en- 
volver uma análise de "suficiência"; passa a evidenciar a importância da avaliação da "capacidade diretiva" do governo e sua administração.

Nessa mesma esteira, o direito administrativo incorpora - como noticiado nesse trabalho - a dimensão da participação, da consensualidade, do controle social, da legitimidade. Todos esses são elementos que se identificam com o conceito de governança - nova temática posta na pauta das reformas - que reverte o domínio das estruturas hierárquicas na formulação das escolhas públicas, em favor de uma opção que se exerce de forma coletiva e política, mais do que individual e econômica, permitindo que o cidadão volte a ser cidadão, posto que readquire sua condição de participante "ativo" dos processos políticos que presidem as grandes escolhas no tema da ação estatal (Peters, 2005:585-598).

Ao quadro supostamente rígido "denunciado" pelo gerencialismo, o que se contrapõe, em verdade, é um direito administrativo aberto às premissas da governança, entendida como o processo de transformação do modo de governar caracterizado pela superação da exclusividade dos poderes públicos na gestão dos assuntos públicos e pelo reconhecimento da pluralidade de agentes sociais com potencialidade efetiva de intervir nesses mesmos assuntos públicos, seja pela atuação direta, pelas relações de interdependência que possam manter com temas confiados originalmente ao Poder Público (Alli Aranguren, 2004:319).

Dessa abertura à sociedade e suas reivindicações e potencialidades traduzida como governança, decorrerá que as funções de "coordenação" e "fomento" passam a se revestir de tanta ou mais importância que as conhecidas funções de outorga de prestações, apresentando-se o Estado - na expressão de Sousa Santos - como o "...novíssimo movimento social...". Significa dizer que a reconfiguração da administração pública - seja em processos mais profundos, de reforma constitucional, seja em iniciativa que se materialize no plano legislativo, tudo isso vai incorporar esse relevantíssimo agente do processo de deliberação, a saber, a sociedade civil por suas múltiplas formas de manifestação.

Duas são as formas, por sua vez, pelas quais a associação da sociedade ao agir estatal pode se verificar. Uma delas diz respeito ao próprio processo de "escolha pública", numa preocupação de democratização das escolhas estatais; outra se reflete no terreno da "concretização das ações", que, embora públicas, não exigem a execução diretamente pelo Estado, como enunciado no plano diretor de reforma do Estado.

\section{Cidadania ativa, escolhas públicas e participação}

No campo do processo de escolha pública, a participação se apontava como elemento legitimador das decisões alocativas desde os primeiros estudos envolvendo a formação da agenda por ocasião da construção das políticas públicas que 
datavam desde os anos 1960 (Kingdon, 1995:105-113). A compreensão da sua importância vem se ampliando desde a consolidação de um conceito de democracia substantiva, que não cabe somente no momento eleitoral, mas que convoca a cidadania a outras dimensões de envolvimento com a res publica.

Os impactos havidos na estrutura e função do Estado noticiados neste artigo, implicando reconhecimento da incapacidade de a administração empreender por si só - e com exclusividade - a identificação do que seja o interesse geral, igualmente incrementam a importância da participação como vetor de configuração da ação estatal, com a referência inclusive a seu papel como signo legitimador dessa mesma atuação da administração, com a formação de verdadeiras "coalizões decisionais" (Sorrentino, 2003:214).

No campo da concretização das ações, a dimensão da participação envolverá o enfrentamento de um problema detectado por Costa (2008:869), que apontava que inobstante o longo percurso de experiências, mais ou menos exitosas de reformas administrativas, "...esse processo de transformação sempre deixou em segundo plano a questão democrática e a teleologia das reformas e da própria máquina pública...".

A identificação desses pontos - necessários - de inserção da sociedade está longe ainda de encontrar o desejável reflexo nas estruturas e no modo de atuação estatal. ${ }^{17}$ Essa autocrítica, mais do que um tom pessimista, nada mais encerra do que a percepção de "novas oportunidades" que se põe aos futuros movimentos de reforma administrativa.

A primeira oportunidade é a de se investir na articulação de "canais efetivos" de incremento da "participação da cidadania nos processos de escolhas públicas"; canais concebidos a partir de uma perspectiva "dialógica", e não unilateral. Significa dizer que a efetiva incorporação da cidadania nos processos de escolha pública envolve não a simples divulgação de dados - afinal, essa prática transparente nada mais é do que a devida reverência ao princípio da publicidade - mas a oferta de uma "arena real de troca de informações e contribuições", que pode e deve se estender não somente à gênese da escolha, mas a todo o processo de sua implementação e, principalmente, de avaliação.

A proposta que aqui se enuncia - por isso a referência da participação a uma agenda de reformas - é de "institucionalização" desse vetor como efetivo (ainda que não o único) signo de "legitimidade da ação estatal", e não como uma iniciati-

\footnotetext{
${ }^{17} \mathrm{O}$ anteprojeto por diversas vezes chamado de Lei Orgânica da Administração, no tema da cidadania ativa, contém referências ao controle social (arts. 28, III; 52; 55; 66 a 68) no modelo mais tradicional, associado à outorga de informações pela via das audiências públicas, direito de petição de outros instrumentos cuja presença no sistema normativo nacional data de pelo menos duas décadas.
} 
va reservada tão somente àquelas hipóteses em que a lei presume uma relevância que justifique a convocação cidadã. ${ }^{18}$

Cidadania ativa - especialmente a cidadania ativa social de que nos fala Cabo Martín ${ }^{19}$ - é um "capital social” que se constrói, por intermédio do exercício permanente. Nesses termos, o exercício da cidadania pela participação cidadã é de ser entendido como um dos aspectos das "funções de fomento" que se apontou assistirem ao Estado; e como tal, "incumbe-lhe induzir a prática", notadamente no âmbito das escolhas que ele empreende.

Mais ainda, é a cidadania ativa informada que permitirá a intensificação dos mecanismos de controle voltados à atuação administrativa pautada por resultados - e não pela forma. Afinal, na lição de Dromi (2005:16), a participação generaliza a consciência social de sua íntima conexão com o melhoramento da qualidade de vida e a consecução do bem comum.

Precioso, para a consecução desse resultado, será a incorporação na agenda de reformas, do tema do dever constitucional de enunciação de políticas públicas (Valle, 2007:7-19) e sua interface com essa abertura à cidadania ativa. Afinal, se de instrumentalização ao agir estatal eficiente se está cogitando, não há como se ter em conta tão somente a sua dimensão institucional, desconhecendo - ou mantendo sob um véu de ocultação - o elemento principal, que é a programação do agir estatal.

Outro elemento que precisa ser potencializado nessa construção da cidadania ativa é a contribuição dos tribunais de contas, que se encontram em franca trajetória ascendente de qualificação, profissionalização e compromisso com seus próprios misteres institucionais. Urge, todavia, a esses mesmos órgãos - porque técnicos, tradicionalmente voltados ao público restrito que dessa mesma expertise técnica compartilhe - absorver também a sua importância na equação da governança construída a partir de uma cidadania ativa, partilhando seu acervo de informações e o capital de conhecimento desenvolvido no exercício do controle externo.

\footnotetext{
${ }^{18}$ A ressalva se faz pela circunstância que hoje o instrumento apontado como típico de participação - audiências e consultas públicas - decorre, ou do voluntarismo do titular do poder (administrador ou mesmo o julgador no âmbito do STF), ou de uma presunção legislativa de relevância, associada normalmente ao montante de investimento envolvido. Esse tratamento parece mais sintonizado ou com uma lógica hierárquica de deliberação quanto à coisa pública, ou ainda com uma visão puramente economicista do que se possa revelar relevante, para uma sociedade a partir de critérios econômicos de decisão.

${ }^{19}$ A cidadania ativa social é referida pelo autor, em oposição a uma cidadania ativa individual, que tem em conta tão somente a veiculação e defesa de seus próprios interesses. "...La ciudadania social, por tanto, desde este punto de vista, lleva a considerar que en una perspectiva jurídico-constitucional (con vistas naturalmente a su efecto social) el individuo no es - en consonancia con los presupuestos anteriormente expuestos - un a priori, sino un resultado, una 'construcción' hecha a partir y en relación con los otros" (Cabo Martín, 2006:57).
} 
Não resta dúvida de que essa institucionalização envolve outros esforços, como a construção de uma linguagem comum, que permita uma participação informada e, portanto, útil ao processo de concretização da escolha pública. Mais ainda, a incorporação desse vetor da institucionalização da participação como cláusula de legitimação envolve uma abertura ao conhecimento não convencional dominado pela tecnocracia e que nem por isso se revelará menos relevante quando o tema é satisfação do interesse público.

É de Bento (2003:225) o destaque de que essa participação é de resultar na "elaboração de um projeto coletivo para atuação administrativa [...]", o que prescinde das tecnicalidades tão caras à burocracia profissionalizada, mas abraça a preocupação com os "...valores, a finalidade, o modelo de administração que se deseja, não individualmente do ponto de vista do consumidor do serviço, individual e isoladamente, mas de forma coletiva e política".

Nem se diga que a proposta é paralisante - na medida em que subordina a ação estatal à participação. O desafio é a construção de um mecanismo que viabilize essa retroalimentação recomendada pela governança, num plano macro de decisão, de molde a que as ações diárias de execução possam ser verificadas normalmente. Se essa participação se dará no plano da orçamentação - como experimentado em nosso próprio país nas iniciativas de orçamento participativo - e/ou em outros momentos de planejamento do agir estatal, esse é o desafio que se propõe inserir na agenda de reflexão.

\section{Modelos de concretização da atuação estatal: flexibilidade institucional e relacional}

No campo da execução do agir, a abertura à participação envolverá, necessariamente, uma efetiva incorporação da "consensualidade como valor", e da "flexibilidade como estratégia", de molde a viabilizar a atração dessa cidadania ativa e organizada à execução das chamadas atividades públicas não estatais.

Construir consenso, raiz da apontada função de fomento, envolve - necessariamente - a capacidade de atrair e, com isso, a possibilidade de flexibilizar a atuação de molde a gerar e preservar a referida atratividade. Um Estado que se propõe ao desenvolvimento de relações de coordenação entre e com agentes múltiplos, originários inclusive da sociedade civil, há de estar instrumentalizado a essa atuação multifacetada - e nesse sentido, a prática de formatação de modelos institucionais estanques para o desenvolvimento dessa ou daquela atividade pode não se revelar mais adequada.

A história recente tem demonstrado que o investimento em "modelos relacionais" tem se revelado mais frutífero do que a construção de "modelos institucio- 
nais". Explica-se: as iniciativas de reforma administrativa operam - no plano da execução do agir estatal - com modelos de instituição oferecidos como alternativas de estruturação da administração a partir do critério de especialização funcional; ou, ainda, com modelos de relações jurídicas a se empreender com terceiros. Na primeira categoria, temos o vasto - vastíssimo - elenco de entidades da administração indireta contemplado no direito pátrio; na segunda, as modalidades contratuais ${ }^{20}$ que, sob diversas denominações, promovem a articulação entre Estado e outrem.

No plano dos modelos institucionais, a partir da perspectiva de que o que orienta a decisão pela descentralização é a especialização de funções, a prática tem sido de intensa "segregação": - a cada nova função que se reconhece cometida ao Estado, ocorre um novo modelo de instituição para sua concretização. Disso resulta uma miríade de possibilidades, sem definição muito precisa de seu âmbito de aplicação. Mais ainda, essa opção pressupõe uma rigidez na atividade a que se dedica o Estado, que atenta contra a realidade de nossos tempos. Assim, a afetação de uma atividade a um determinado modelo institucional se dá tendo em conta as características e o regime jurídico próprio àquela atividade naquele momento - mas isso não significa que esse dado remanescerá igual por muito tempo. ${ }^{21}$

Num modelo de rigidez, o resultado é a impossibilidade de conjugação numa mesma entidade, de múltiplas atividades; ou, ainda, a superveniência de uma inadequação institucional que deixa a administração com o problema da transformação ou extinção da entidade indireta que se revela agora, inapropriada ao desenvolvimento daquela função.

A pluralidade de "modelos institucionais", portanto - retomando a afirmação supra - , está a revelar uma preocupação que sobrevaloriza a forma sobre a finalidade; transforma o desenho institucional em fim, quando, na verdade, ele há de ser instrumental à atividade que àquela entidade se delegará. Assim, uma reforma administrativa - particularmente, uma iniciativa como a concretizada pelo Ministério do Orçamento, Planejamento e Gestão já referida - há de prestigiar menos a pluralidade institucional e mais a flexibilidade dessas mesmas estruturas, para receberem e se readaptarem às funções demandadas do Estado do século XXI.

\footnotetext{
${ }^{20}$ Compreenda-se nessa referência as modalidades contratuais, desde os contratos administrativos típicos, regidos pela Lei no 8.666/93, passando também pelos que orientam relações internas à administração (art. 37, §9으. CF), alcançando ainda os contratos que expressam delegação de serviços (Leis $\mathrm{n}^{\circ \mathrm{os}}$ 8.987/95, 11.079/04 e 11.107/05), e relações de supervisão no desenvolvimento de atividades públicas não estatais (Leis noㅗ 9.637/98 e 9.790/99).

${ }^{21}$ Exemplo típico dessa perplexidade se tem em relação ao regime jurídico das empresas públicas e sociedades de economia mista, que, fundado numa diferenciação entre executoras de serviços públicos e interventoras no domínio econômico, encontra hoje as dificuldades inerentes à exclusão de atividades do conceito constitucional de serviço público stricto sensu, o que leva uma mesma entidade - exemplo de viveiro é sempre a ECT - a conjugar prestação de serviço público e intervenção no domínio econômico.
} 
A pluralidade de "modelos relacionais" está a merecer mais investimento da doutrina do que propriamente da produção legislativa. Afinal, as alternativas se multiplicam no plano normatizado. Todavia, os avanços doutrinários são mais expressivos em alguns campos do que nos demais. Assim é que o tema das concessões clássicas de serviços públicos foi prontamente objeto de atenção e importante produção doutrinária. Sua subespécie identificada como parceria público-privada tem sido objeto de maior resistência, com produção bem menos extensa - o que decerto deita seus reflexos na concretização das iniciativas revestidas dessa modalidade negocial. ${ }^{22}$

A figura do contrato de gestão, por outro lado, encontra mais atenção quando associada às relações entre administração e o terceiro setor, ${ }^{23}$ do que na figura prevista no art. $37, \S^{9^{\circ}} \mathrm{CF}$ - inobstante esta última modalidade encontre mais de 10 anos de preceituação.

Finalizando a ilustração, os contratos de programa e de rateio preconizados pela Lei n⿳0 11.107/2005 têm merecido pouca atenção de parte dos comentadores, quando a referida inovação legislativa decorreu justamente dos reclamos de instabilidade dos vínculos conveniais, o que estaria a apequenar as potencialidades desse tipo de ajuste.

Em síntese, a definição dos modelos institucionais de concretização da ação estatal é de encontrar na flexibilidade preceitual sua pedra de toque. Essa orientação, todavia, se revelará inútil se a doutrina não oferecer, em contrapartida, seu esforço de criação no aprofundamento das possibilidades desses arranjos institucionais, a partir da moldura principiológica que a constituição oferece e dos compromissos finalísticos que ela mesma traça.

\section{Direito administrativo, reforma administrativa e direito da governança pública}

Incerteza, contingência e desmistificação foram palavras que inauguraram as presentes considerações. São esses vetores que inspiram igualmente suas conclusões.

\footnotetext{
${ }^{22}$ Não se pode desconhecer que o administrador público tem em conta - evidentemente - a margem de risco jurídico na concretização de suas iniciativas. Assim, se uma modalidade negocial é objeto mais de críticas do que de construção doutrinária, é natural que ela seja não descartada, quando menos secundarizada na escala de prioridades da administração pública.

${ }^{23} \mathrm{O}$ exemplo é significativo no tema das relações entre organizações sociais e Estado no campo da saúde, em que a forte profissionalização dos parceiros do terceiro setor tem proposto a configuração de novas modalidades relacionais cujo desenho, a rigor, só pode partir de quem tem expertise no tema e percebe outras arquiteturas possíveis de relação, no melhor espírito da governança, destinadas ao desenvolvimento daquela atividade pública não estatal. A experiência segue, e com êxito, à conta da flexibilidade que é própria do instrumento - contrato de gestão - que admite resiliência suficiente para recepcionar os novos parâmetros de relacionamento que a experiência concreta sugere.
} 
O Estado muda porque a sociedade muda e com eles muda o direito - não necessariamente na mesma medida e velocidade. $\mathrm{O}$ pluralismo traz o dissenso e a necessidade de adaptação para a ordem do dia - e com isso, a perspectiva de que a reforma da administração se transforme num exercício permanente desenvolvido no âmbito do direito administrativo e não num evento pautado por grandes e retumbantes decisões políticas.

Incorporar os novos paradigmas da pós-modernidade, como vem fazendo a melhor doutrina nacional, ${ }^{24}$ é a evidência máxima de que, ao contrário da imputação referida por parte dos gerencialistas, de que o direito administrativo é rígido, essa ciência vem se dedicando, criativa e propositivamente, à transformação da administração pública para a conciliação de seu agir como poder, aos compromissos que a constituição lhe traçou. Essa transformação, todavia, jamais será finalizada - e o que se aponta a título de conclusão, como provocação à continuidade desse trabalho de permanente atualização de sentido do direito administrativo, é a advertência de Mockle (2007) em relação à temática que se insinua no direito público em geral: a ausência de abertura à realidade da governança pode contribuir para despi-lo de sua chama de vida, sem ter em conta a amplitude das transformações em curso.

Nesse momento, cumpre associarem-se os esforços - de reforma, e de reflexão teórico-doutrinária - para que o exercício do poder, por intermédio do direito administrativo, siga orientado à liberdade.

\section{Referências}

ABRÚCIO, Fernando Luiz. Trajetória recente da gestão pública brasileira: um balanço crítico e a renovação da agenda de reformas. Revista de Administração Pública. Edição especial comemorativa 1967-2007, p. 67-86, 2007.

AGUILAR VILLANUEVA, Luis F. Gobernanza y gestión pública. México: FCE, 2006.

ALLI ARANGUREN, Juan-Cruz. Derecho administrativo y globalización. Prólogo de Antonio Garrigues Walker. Madrid: Thomson Civitas, 2004.

ARAGÃO, Alexandre dos Santos; MARQUES NETO, Floriano de Azevedo. Direito administrativo e seus novos paradigmas. Belo Horizonte: Fórum, 2009.

BELTRÁN VILLALVA, Miguel. La acción pública en el régimen democrático. Madrid: Centro de Estudios Políticos y Constitucionales, 2000.

\footnotetext{
${ }^{24}$ Os trabalhos pioneiros de Diogo de Figueiredo e Odete Medauar abriram caminho a uma vasta produção orientada à prospectiva no campo do direito administrativo, que encontra continuidade nos próprios autores originais em seu permanente trabalho de revisão e atualização, como também em toda uma nova geração de administrativistas brasileiros (Moreira Neto, 2007; Medauar, 2009; Aragão e Marques Neto, 2009).
} 
BENTO, Leonardo Valles. Governança, governabilidade e reforma do Estado: entre eficiência e democratização. Barueri: Manole, 2003.

CABANES, Arnaud. Essai sur la gouvernance publique. Un constat sans concession... quelquer solutions sans idéologie. Préface de Jérôme Monod. Paris: Gualino Éditeur, 2004.

CABO MARTÍN, Carlos de. Teoría constitucional de la solidariedad. Madrid: Marcial Pons, 2006.

CHEVALLIER, Jacques. O Estado pós-moderno. Trad. de Marçal Justen Filho do original L'État post-moderne. Belo Horizonte: Fórum, 2009.

COSTA, Frederico Lustosa da. Brasil: 200 anos de Estado, 200 anos de administração pública, 200 anos de reformas. Revista de Administração Pública, v. 5, n. 42, p. 829-874, 2008.

DIXON, Rosalind. Creating dialogue about socio-economic rights: strong $v$. weakform judicial review revisited. International Journal of Constitutional Law, v. 5, p. 391-418, jul. 2007.

DROMI, Roberto. Modernización del control público. Madrid-Mexico: Editorial Hispania Libros, 2005.

FRIEDMAN, Barry. The politics of judicial review. Texas Law Review, v. 84, p. 257, 2005.

GARCÍA NIETO, Alejandro. El desgobierno de lo público. Barcelona: Ariel, 2008.

KINGDON, John W. Agenda setting. In: THEODOULOU, Stella Z.; CAHN, Matthew A. Public policy. The essential readings. New Jersey: Prentice Hall, 1995.

LOPES, Júlio Aurélio Vianna. A Carta da democracia. O processo constituinte de ordem pública de 1988. Rio de Janeiro: Topbooks, 2008.

MEDAUAR, Odete. Direito administrativo moderno. 13. ed., revista e atualizada. São Paulo: Revista dos Tribunais, 2009.

MENDES, Gilmar Ferreira. Direitos fundamentais e controle de constitucionalidade. Estudos de direito constitucional. 3. ed., 2. tir. rev. e ampl. São Paulo: Saraiva, 2004. MOCKLE, Daniel. La gouvernance, Le droit et l'État. La question du droit dans la gouvernance publique. Bruxelles: Bruylant, 2007.

MOREIRA NETO, Diogo de Figueiredo. Mutações do direito administrativo. 3. ed. rev. e ampl. Rio de Janeiro: Renovar, 2007.

OST, François ; KERCHOVE, Michel van de. De la pyramide au réseau?: pour une théorie dialectique du droit. Bruxeles: Faculter Universitaires Saint-Louis, 2002. 
PETERS, B. Guy. Gobernanza y burocracia pública: nuevas formas de democracia o nuevas formas de control? Foro Internacional, n. 182, ano XLV, p. 585-598, 2005.

REZENDE, Flávio da Cunha. Por que reformas administrativas falham? Revista Brasileira de Ciências Sociais, v. 17, n. 50. São Paulo, out. 2002. Disponível em: $<$ http://www.scielo.br/scielo.php?script=sci_arttext\&pid=S01026909200200030000 8\&lng=en\&nrm=iso>. Acesso em: 29 ago. 2009.

- Desafios gerenciais para a reconfiguração da administração burocrática brasileira. Sociologias, n. 21, p. 359, 2009.

RODRÍGUEZ-ARANDA MUNÕZ, Jaime. La vuelta al derecho administrativo (a vueltas con lo privado y lo publico). AEC Revista de Direito Administrativo e Constitucional, ano 5, n. 20, p. 11-39, abr./jun. 2005.

. Reforma administrativa y nuevas políticas públicas. Caracas: Editorial Sherwood, 2005.

. El buen gobierno y la buena administración de instituciones públicas. Adaptado a la Ley 5/2006, de 10 de abril. Navarra: Editorial Aranzadi, 2006.

SECCHI, Leonardo. Modelos organizacionais e reformas da administração pública. Revista de Administração Pública, v. 43, n. 2. Rio de Janeiro, abr. 2009. Disponível em: <http://www.scielo.br/scielo.php?script=sci_arttext\&pid=S00347612200900020 0004\&lng=en\&nrm=iso>. Acesso em: 29 ago. 2009.

SORRENTINO, Giancarlo. Diritti e partecipazione nell'amministrazione di risultato. Napoli: Editoriale Scientifica, 2003.

SOUSA SANTOS, Boaventura. Reinventar la democracia, reinventar el Estado. Buenos Aires: Consejo Latinoamericano de Ciências Sociales (CLASCO), 2006.

VALLE, Vanice Regina Lírio do. Controle social: promovendo a aproximação entre administração pública e a cidadania. Prêmio Serzedello Corrêa 2001 - Monografias Vencedoras - Perspectivas para o controle social e a transparência da administração pública. Brasília: TCU, Instituto Serzedello Corrêa, p. 75-139, 2002.

. Dever constitucional de enunciação de políticas públicas e autovinculação: caminhos possíveis de controle jurisdicional. Fórum Administrativo, v. 82, p. 7-19, 2007.

. O direito narciso: nova ameaça à jusfundamentalidade dos direitos. $A \mathcal{E} C$. Revista de Direito Administrativo E Constitucional, v. 28, p. 27-44, 2007.

WERNECK VIANNA, Luiz. O terceiro poder na Carta de 1988 e a tradição republicana: mudança e conservação. In: OLIVEN, R. G. et al (Orgs.). A Constituição de 1988 na vida brasileira. São Paulo: Hucitec/Anpocs/Fundação Ford, 2008. 